\title{
An examination of co-infection in acute gastroenteritis and histo-blood group antigens leading to viral infection susceptibility
}

\author{
KENTA FURUYA, HITOSHI NAKAJIMA, YOUSUKE SASAKI and YOSHIHISA URITA \\ Department of General Medicine and Emergency Care, Toho University School of Medicine, \\ Omori Hospital, Tokyo 143-8541, Japan
}

Received August 3, 2015; Accepted January 21, 2016

DOI: $10.3892 /$ br.2016.585

\begin{abstract}
The aim of the present study was to evaluate co-infection in the gastrointestinal tract in terms of viruses, bacteria and the ABO blood group. We hypothesized that a combination of norovirus (NV) and bacteria in the gastrointestinal tract could affect the likelihood of an individual to contracting NV. Histo-blood group antigens (HBGAs) are considered to act as receptors that can lead to NV susceptibility. In addition to genetics, co-infection in the gastrointestinal tract may be associated with this mechanism. A total of 370 patients with acute gastroenteritis presenting with diarrhea (14-89 years) were recruited. The male/female ratio was 20/17. Single infection (bacteria or virus), co-infection with two viruses, and co-infection with one virus and one bacterium were statistically analyzed. In total, 88 of the 376 subjects (23.4\%) were positive for one virus, and 50 (13.3\%) were positive for one bacterium. Co-transfection with bacteria and a virus were detected in 46 (47.9\%) of the 96 bacterial gastroenteritis cases Statistical analysis revealed that co-infection of bacteria and $\mathrm{NV}$ was not significant in all viral infections $(\mathrm{P}=0.768)$. In terms of the ABO histo-blood group type and NV infection, the frequency in the $\mathrm{O}$ type was not significantly increased $(\mathrm{P}=0.052)$. Co-infection of bacteria and a virus occurred frequently in the gastrointestinal tract. The ABO blood phenotype expression was not a significant factor in NV infection in the present case series and the results did not suggest an affinity of NV for specific bacteria.
\end{abstract}

\section{Introduction}

Causative agents of infectious gastroenteritis include viruses, bacteria and cryptosporidium. Subsequent to a short incubation

Correspondence to: Dr Kenta Furuya and Dr Hitoshi Nakajima, Department of General Medicine and Emergency Care, Toho University School of Medicine, Omori Hospital, 6-11-1 Omori-Nishi, Tokyo 143-8541, Japan

E-mail: emmanuelpetit1717@yahoo.co.jp

E-mail: nakaji_ma521@yahoo.co.jp

Key words: histo-blood group antigens, co-infection, norovirus, ABO blood phenotype, norwalk virus period following oral infection, symptoms such as vomiting, diarrhea, abdominal pain and fever appear (1). As causative viruses, rotavirus (RV), adenovirus (AV) and norovirus (NV) are common, and NV is the most dominant. Differences in the viral epidemic pattern can be observed among countries, regions and climates (2).

Histo-blood group antigens (HBGAs) have been recognized as receptor tissue for NV that is associated with infection of the host. Lewis-positive individuals can have HBGAs on the surface of epithelial cells and NV have an affinity through blood-type substances, which are expressed in intestinal epithelial cells (3). As HBGAs are considered to act as NV receptors and lead to NV susceptibility, we hypothesized that in addition to genetics, co-infection in the gastrointestinal tract could be associated with this mechanism. The present study aimed to investigate the association between bacterial infection and co-infection in acute gastroenteritis and HBGAs, and further studies are also important to evaluate the results.

\section{Patients and methods}

Baseline characteristics of subjects. The study is a single-center retrospective cohort study. All the clinical and laboratory data and preoperative backgrounds were reviewed from patient medical records from Toho University School of Medicine, Omori Hospital (Tokyo, Japan). A total of 370 patients with acute gastroenteritis who presented with diarrhea (age, 14-89 years; mean age, 37.0 years) (Table I) were recruited. The male/female ratio was 20/17. Single infection (bacteria or virus), co-infection with two viruses, and co-infection with one virus and one bacterium were statistically analyzed.

Diagnosis of acute gastroenteritis. All the patients were diagnosed with acute gastroenteritis according to acute onset and acute diarrhea without any diarrhea-inducing baseline illness. Other symptoms such as nausea, fever or abdominal pain were not considered.

Examination tools. Patient stool samples were collected and kits were used to examine for antigens of NV, RV and AV. Stool cultures for pathogenic bacteria were also performed using the same stool samples. The examination tool for NV in Japan is QUICKNAVI-NORO ${ }^{\text {тм }}$ (Otsuka Pharmaceutical Co., Tokyo, Japan). The measurement principle is immunochromatography 
and the targets are NV genogroups I and II. The sensitivity and specificity were 81.6 and $96.9 \%$, respectively, compared to the previously used reverse transcription polymerase chain reaction (RT-PCR) method. The examination tool for RV and $\mathrm{AV}$ is BD Rota/Adeno Examan Stick ${ }^{\mathrm{TM}}$ (BD Biosciences, San Diego, CA, USA). The measurement principle is immunochromatography and the targets are AV B3, B7, F40, F41, RV AG1WA and AG3SA11. Compared to the previously used kit, the sensitivity and specificity were $\sim 95 \%$. Stool cultures for pathogenic bacteria were ordered without any species targeted under routine measurement.

Statistical analysis. All the clinical and laboratory data were collected from patient medical records. Continuous variables are expressed as the mean \pm standard deviation unless otherwise stated and were compared using the Mann-Whitney $\mathrm{U}$ test. Categorical variables were compared using the $\chi^{2}$ test. Cox proportional hazards regression analysis was used to identify variables that were significant predictors of survival. $\mathrm{P}<0.05$ was considered to indicate a statistically significant difference. All the statistical analyses were performed using SPSS version 11.0 (SPSS, Inc., Chicago, IL, USA).

Ethics. The present study was approved by the Institutional Review Board of Toho University Omori Medical Center (project approval number: 20-106).

\section{Results}

Viral and bacterial content of each infection. In total, 88 of the 376 subjects (23.4\%) were positive for a virus only, and $50(13.3 \%)$ were positive for bacteria only. The presence of bacteria and a virus was detected in 46 (47.9\%) of the 96 bacterial gastroenteritis cases (Table II). Fourteen species of bacteria were detected, including Campylobacter [33/96 (36.4\%)], enteropathogenic Escherichia coli [E.coli; 31/96 (34.1\%)] and enterotoxigenic E. coli [30/96 (33.0\%)] (Fig. 1). The mean ages of the infected patients were $50.0 \pm 24.6,36.3 \pm 15.8$ and $38.6 \pm 18.3$ years, respectively. RV gastroenteritis was detected in 92 patients (24.7\%; co-infection 83.7\%), AV gastroenteritis in 95 (25.5\%; co-infection 86.3\%), and NV co-infection gastroenteritis in 93 (24.9\%; co-infection 35.4\%). Of the co-infection with a virus and bacteria cases, $27.2 \%$ had RV, $27.4 \%$ had AV and $19.4 \%$ had NV. Co-infection with bacteria and NV was not significant in all viral infections $(\mathrm{P}=0.768)$ (Fig. 2). The correlation between the serum values of $\mathrm{C}$-reactive protein (CRP) and white blood cells (WBCs) and co-infection was analyzed. Co-infection was evaluated by WBC count not by $\mathrm{CRP}(\mathrm{P}=0.03)$. In terms of the $\mathrm{ABO}$ histo-blood group type and $\mathrm{NV}$ infection, the frequency in O-type patients was not significantly increased $(\mathrm{P}=0.052)$, although the cumulative number of patients was the largest among the $\mathrm{ABO}$ blood groups (Table III).

\section{Discussion}

Causative agents of infectious gastroenteritis include viruses, bacteria and cryptosporidium. Subsequent to a short incubation period following oral infection, symptoms such as vomiting, diarrhea, abdominal pain and fever appear (1). As causative viruses, $\mathrm{RV}, \mathrm{AV}$ and $\mathrm{NV}$ are common, and $\mathrm{NV}$ is the
Table I. Baseline characteristics of the subjects.

Characteristics

Total, $\mathrm{n}=370$

\begin{tabular}{lc} 
Male, $\mathrm{n}$ & 200 \\
Female, $\mathrm{n}$ & 170 \\
Median age (range), year & $37(14-89)$ \\
Norovirus, $\mathrm{n}$ & 93 \\
Rotavirus, $\mathrm{n}$ & 92 \\
Adenovirus, $\mathrm{n}$ & 95 \\
Bacteria, $\mathrm{n}$ & 96 \\
Virus + virus, $\mathrm{n}$ & 62 \\
Virus + bacteria, $\mathrm{n}$ & 46 \\
\hline
\end{tabular}

most dominant. Differences in the viral epidemic pattern can be observed among countries, regions and climates (2).

$\mathrm{RV}$ belongs to the Reoviradae family and infects the intestinal tract. RVs can be divided into groups A through $\mathrm{C}$, with group B being the most common cause of severe diarrhea in adults. Although rare, the association of RV with diseases outside the intestinal tract, such as the central nervous system, has been suggested. The distribution of viruses in extraintestinal organs has been confirmed in animal experiments (4-6). AV belongs to the Adenoviridae family. AV infections often present as conjunctivitis, tonsillitis (which may appear to be identical to strep throat and cannot be distinguished from strep except by throat culture), ear infection or croup. AV types 40 and 41 can also cause gastroenteritis (7). NV is classified as part of the Caliciviridae family and infects the intestinal tract. It is broadly classified into genogroups I and II $(8,9)$.

The RT-PCR/enzyme-linked immonosorbent assay method has been approved as a diagnostic kit and has prevailed over the conventional immune electron microscopy/radioimmunoassay method. HBGAs have been recognized as receptor tissue for $\mathrm{NV}$ that is associated with infection of the host (3). ABO blood group substances and Lewis blood-type substances are expressed in intestinal epithelial cells in $\sim 84 \%$ of Japanese individuals. Lewis-positive individuals can have HBGAs on the surface of epithelial cells. NV is reported to have an affinity to these HBGAs and can recognize them as receptors. It has been reported that the incidence of infection in individuals with blood types $\mathrm{A}$ and $\mathrm{O}$, and secretion-type individuals is higher than that of the individuals with blood type B and non-secretion-type individuals (10). In the present study, this significant difference could not be confirmed.

For all infectious diseases, not just viral gastroenteritis, a rapid serological diagnosis is important. The prevention of infectious spread is important, and the accurate differential diagnosis of bacteria or other causes is required. It is essential for prompt measures to be taken to protect against outbreaks in facilities. The basic rapid diagnostic method is the antigen-antibody reaction, in which soluble viral protein antigen and antibody react in the ion chromatography method. The sensitivity and specificity maintain an adequate level $(>90 \%)$ with the aforementioned kits (i.e., QUICKNAVI-NORO ${ }^{\mathrm{TM}}$ and BD Rota/Adeno Examan Stick $^{\mathrm{TM}}$ ), and are adequate rapid diagnostic methods. Rapid 
Table II. Viral and bacterial content of each infection.

\begin{tabular}{|c|c|}
\hline Content of each infection & Cases, $\mathrm{n}$ \\
\hline NV total & 93 \\
\hline Only NV & 60 \\
\hline $\mathrm{NV}+\mathrm{AV}$ & 4 \\
\hline $\mathrm{NV}+\mathrm{RV}+\mathrm{AV}$ & 11 \\
\hline $\mathrm{NV}+$ bacteria & 15 \\
\hline $\mathrm{NV}+\mathrm{AV}+$ bacteria & 1 \\
\hline $\mathrm{NV}+\mathrm{RV}+\mathrm{AV}+$ bacteria & 2 \\
\hline RV total & 92 \\
\hline Only RV & 15 \\
\hline $\mathrm{RV}+\mathrm{AV}$ & 41 \\
\hline $\mathrm{RV}+\mathrm{NV}+\mathrm{AV}$ & 11 \\
\hline $\mathrm{RV}+$ bacteria & 5 \\
\hline $\mathrm{RV}+\mathrm{AV}+$ bacteria & 18 \\
\hline $\mathrm{RV}+\mathrm{NV}+\mathrm{AV}+$ bacteria & 2 \\
\hline AV total & 95 \\
\hline Only AV & 13 \\
\hline $\mathrm{AV}+\mathrm{NV}$ & 4 \\
\hline $\mathrm{AV}+\mathrm{RV}$ & 41 \\
\hline $\mathrm{AV}+\mathrm{NV}+\mathrm{RV}$ & 11 \\
\hline $\mathrm{AV}+$ bacteria & 5 \\
\hline $\mathrm{AV}+\mathrm{NV}+$ bacteria & 1 \\
\hline $\mathrm{AV}+\mathrm{RV}+$ bacteria & 18 \\
\hline $\mathrm{AV}+\mathrm{NV}+\mathrm{RV}+$ bacteria & 2 \\
\hline Bacteria total & 96 \\
\hline Only bacteria & 50 \\
\hline Bacteria $+\mathrm{NV}$ & 15 \\
\hline Bacteria + RV & 5 \\
\hline Bacteria + AV & 5 \\
\hline Bacteria + NV + AV & 1 \\
\hline Bacteria + RV + AV & 18 \\
\hline Bacteria + NV + RV + AV & 2 \\
\hline
\end{tabular}

$\mathrm{NV}$, norovirus; $\mathrm{RV}$, rotavirus; $\mathrm{AV}$, adenovirus.

Table III. Norovirus infection analysis by the ABO blood type.

\begin{tabular}{llllr}
\hline Infection & $\mathrm{O}, \mathrm{n}$ & $\mathrm{A}, \mathrm{n}$ & $\mathrm{B}, \mathrm{n}$ & $\mathrm{AB}, \mathrm{n}$ \\
\hline Norovirus $^{+}$ & 28 & 26 & 14 & 1 \\
Norovirus $^{-}$ & $34^{\mathrm{a}}$ & 37 & 22 & 17 \\
Total & 62 & 63 & 36 & 18 \\
\hline
\end{tabular}

${ }^{\mathrm{a}} \mathrm{P}=0.052$

diagnostic methods can contribute to the suppression of infectious spread.

In the developed world, Campylobacter jejuni is the primary cause of bacterial gastroenteritis, with half of these cases associated with exposure to poultry (11). E. coli and Salmonella shigella are other types of source bacteria (12).

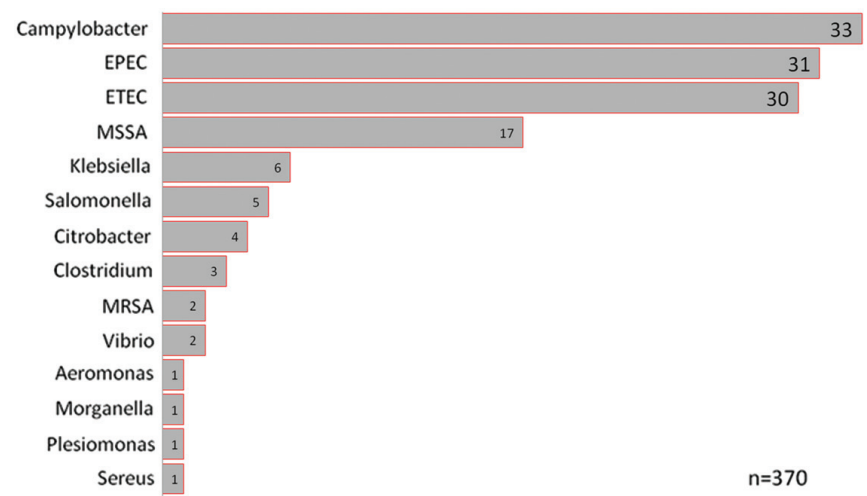

Figure 1. Bacterial species detected in co-infection in acute gastroenteritis. Campylobacter species were identified most frequently in this series.

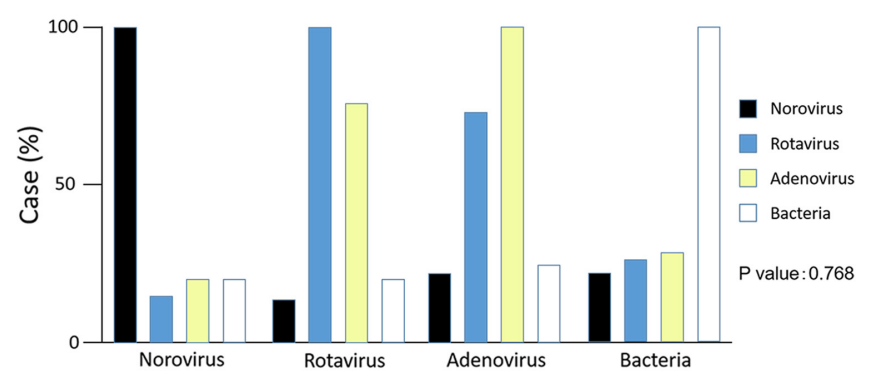

Figure 2. Co-infection in acute gastroenteritis according to each virus and bacteria. Co-infection of bacteria and norovirus was not significant in all virus infections $(\mathrm{P}=0.768)$.

When food becomes contaminated with bacteria and remains at room temperature for a period of several hours, the bacteria multiply and increase the risk of infection in those who consume the food. Certain foods commonly associated with illness include raw or undercooked meat, poultry, seafood and eggs; raw sprouts; unpasteurized milk and soft cheeses; and fruit and vegetable juice (13). In the present study, Campylobacter and E. coli were mainly detected, consistent with the previous study.

The frequency of sporadic NV infection is greater than that of RV and AV. Co-infection of RV and AV occurred frequently. As such, RV and AV may not be able to function well alone and may require a co-worker to trigger an infection. The involvement of HBGAs can be considered to heighten the single infection rate of NV; however, the exact association remains to be elucidated and further research is required. Although it has been thought that NV is specific for co-infection with a bacterial infection compared to RV and $\mathrm{AV}$, this was not demonstrated in the present study. We assume that indigenous bacteria in the intestinal tract and bacterial infection is associated with viral infection. The increasing number of NV infections may be associated with indigenous bacteria in the intestinal tract and bacterial infection. HBGAs are believed to affect the transmission and infection processes of NV and bacteria. Further studies of bacteria and their binding capacity to viruses will provide new insights (14). The presence of blood group-active enteric bacteria, such as E.coli, Salmonella and Klebsiella, has been reported and $\sim 50 \%$ of the strains inhibited anti-blood group ABO agglutinins (15). 
The blood group activities of enteric bacteria were attributed to the presence of HBGA-like $\mathrm{O}$ antigen in lipopolysaccharide (LPS) (16). Bacterial LPS has been shown to have a key role in the infection of mouse mammary tumor virus. The gut microbiota in the human intestine also affects the likelihood of infection with human enteric viruses (17). Elevation in the levels of antigen in the intestine is believed to provide an opportunity for NV infection and could also affect other gastroenteritis virus infections, such as RV $(18,19)$. NV is believed to be specific for co-infection with bacteria; however in the present study, it is suggested that co-infection with bacteria is not confined to NV. The serum values of WBCs and the CRP of co-infection cases (virus and bacteria) are higher than those of single infection (virus). In case of elevated serum values of inflammatory markers, the involvement of bacterial infection should be considered.

The Norwalk virus strain 68, which is the prototype of NV, is absorbed in blood type $\mathrm{A}$ and $\mathrm{O}$ antigen and secretion-type antigen (20). The blood group antigens are also expressed in intestinal epithelial cells, not just on the surface of human red blood cells. A previous study reported that the villi of the jejunum affected by NV are flattened and atrophied (21). In vitro binding assay using virus-like particles (VLPs) has revealed that the incidence of infection in individuals with blood type $\mathrm{A}$ and $\mathrm{O}$ and secretion-type individuals are higher than that of individuals with blood type B and non-secretion-type individuals (22). Evaluation is difficult as the diagnosis of Lewis blood type was not performed in Omori Hospital. This only pertains to the Norwalk virus strain 68 , and it is clear that not all NV strains recognize the blood group antigen in the same manner as the Norwalk virus strain 68.

Infection was shown to occur equally in individuals with A, $B$ and $\mathrm{O}$ blood types in the GII/4 genotype, which can be severe and can spread easily $(23,24)$. In the present study, there was no significant difference in the infection rate among $\mathrm{ABO}$ blood types in NV infection; the results were similar for RV and AV. It is not clear whether HBGAs are only involved in absorption between cells and NV, or if they invade the intestinal tract. Clarification of the mechanism of NV infection beginning with the adsorption to HBGAs requires elucidation in future studies.

In conclusion, co-infection of bacteria and virus occurred frequently in the gastrointestinal tract. The $\mathrm{ABO}$ blood phenotype expression was not significant in the present series of NV infections and the results did not suggest the affinity of $\mathrm{NV}$ for specific bacteria. However, it was suggested that there could be another pathway leading to infectious diarrheal disease in addition to the correlation between the genetically determined HBGA expression of an individual and their susceptibility to an enteric virus, particularly NV.

\section{References}

1. Bryce J, Boschi-Pinto C, Shibuya K and Black RE; WHO Child Health Epidemiology Reference Group: WHO estimates of the causes of death in children. Lancet 365: 1147-1152, 2005.

2. Parashar UD, Gibson CJ, Bresee JS and Glass RI: Rotavirus and severe childhood diarrhea. Emerg Infect Dis 12: 304-306, 2006.
3. Kageyama T, Kojima S, Fukushi S, Hoshino FB, Shinohara M, Uchida K, Natori K, Takeda $\mathrm{N}$ and Katayama K: Genogroup-specific PCR primers for detection of Norwalk-like viruses. J Virol Methods 100: 107-114, 2002.

4. Azevedo MS, Yuan L, Jeong KI, Gonzalez A, Nguyen TV, Pouly S, Gochnauer M, Zhang W, Azevedo A and Saif LJ: Viremia and nasal and rectal shedding of rotavirus in gnotobiotic pigs inoculated with Wa human rotavirus. J Virol 79: 5428-5436, 2005.

5. Crawford SE, Patel DG, Cheng E, Berkova Z, Hyser JM, Ciarlet M, Finegold MJ, Conner ME and Estes MK: Rotavirus viremia and extraintestinal viral infection in the neonatal rat model. J Virol 80: 4820-4832, 2006.

6. Fenaux M, Cuadras MA, Feng N, Jaimes M and Greenberg HB: Extraintestinal spread and replication of a homologous EC rotavirus strain and a heterologous rhesus rotavirus in BALB/c mice. J Virol 80: 5219-5232, 2006.

7. Waddell G, Whelan G and Bock G: Novel diarrhoea viruses. Wiley, New York, p63, 1987.

8. Okada M, Ogawa T, Kaiho I and Shinozaki K: Genetic analysis of noroviruses in Chiba Prefecture, Japan, between 1999 and 2004. J Clin Microbiol 43: 4391-4401, 2005.

9. Hansman GS, Natori K, Shirato-Horikoshi H, Ogawa S, Oka T, Katayama K, Tanaka T, Miyoshi T, Sakae K, Kobayashi S, et al: Genetic and antigenic diversity among noroviruses. J Gen Virol 87: 909-919, 2006.

10. Hutson AM, Atmar RL, Graham DY and Estes MK: Norwalk virus infection and disease is associated with $\mathrm{ABO}$ histo-blood group type. J Infect Dis 185: 1335-1337, 2002.

11. Galanis E: Campylobacter and bacterial gastroenteritis. CMAJ 177: 570-571, 2007.

12. Webb A and Starr M: Acute gastroenteritis in children. Aust Fam Physician 34: 227-231, 2005.

13. Nyachuba DG: Foodborne illness: Is it on the rise? Nut Rev 68: 257-269, 2010.

14. Miura T, Sano D, Suenaga A, Yoshimura T, Fuzawa M, Nakagomi T, Nakagomi O and Okabe S: Histo-blood group antigen-like substances of human enteric bacteria as specific adsorbents for human noroviruses. J Virol 87: 9441-9451, 2013.

15. Springer GF, Wiiliamson P and Brandes WC: Blood group activity of gram-negative bacteria. J Exp Med 113: 1077-1093, 1961.

16. Andersson M, Carlin N, Leontein K, Lindquist U and Slettengren K: Structural studies of the O-antigenetic polysaccharide of Escherichia coli O86, which possesses blood-group B activity. Carbonhydr Res 185: 211-223, 1989.

17. Kane M, Case LK, Kopaskie K, Kozlova A, MacDearmid C, Chervonsky AV and Golovkina TV: Successful transmission of a retrovirus depends on the commensal microbiota. Science 334: 245-249, 2011.

18. Hu L, Crawford SE, Czako R, Cortes-Penfield NW, Smith DF, Le Pendu J, Estes MK and Prasad BV: Cell attachment protein VP8* of a human rotavirus specifically interacts with A-type histo-blood group antigen. Nature 485: 256-259, 2012.

19. Huang P, Xia M, Tan M, Zhong W, Wei C, Wang L, Morrow A and Jiang X: Spike protein VP8* of human rotavirus recognize histo-blood group antigens in a type-specific manner. J Virol 86: 4833-4843, 2012.

20. Shirato-Horikoshi $\mathrm{H}$ and Takeda N: Interaction between norovirus and human histo-blood group antigens. Uirusu 57: 181-189, 2007 (In Japanese).

21. Graham DY, Jiang X, Tanaka T, Opekun AR, Madore HP and Estes MK: Norwalk virus infection of volunteers: New insights based on improved assays. J Infect Dis 170: 34-43, 1994.

22. Lindesmith L, Moe C, Marionneau S, Ruvoen N, Jiang X, Lindblad L, Stewart P, LePendu J and Baric R: Human susceptibility and resistance to Norwalk virus infection. Nat Med 9: 548-553, 2003.

23. Okada M, Tanaka T, Oseto M, Takeda N and Shinozaki K: Genetic analysis of noroviruses associated with fatalities in healthcare facilities. Arch Virol 151: 1635-1641, 2006.

24. Rockx BH, Vennema H, Hoebe CJ, Duizer E and Koopmans MP: Association of histo-blood group antigens and susceptibility to Norovirus infections. J Infect Dis 191: 749-754, 2005. 